\title{
Los efectos jurídicos de la separación judicial y divorcio por causal en la patria potestad
}

María Consuelo Barletta Villarán

La relación paterno filial es jurídicamente afectada por la influencia del divorcio sanción, cuando se establece en la legislación de familia, la suspensión de la patria potestad al cónyuge culpable del decaimiento o disolución del vínculo.

Este efecto jurídico, es plausible de crítica y revisión a la luz de los principios de la doctrina de la protección integral, que conciben al niño(a) y adolescente como sujetos con derechos específicos, cuyo Interés Superior ha de ser resguardado en toda intervención judicial.

Este trabajo pretende aportar nuevos lineamientos para la discusión, en una problemática que cuestiona la naturaleza jurídica de la patria potestad, y busca poner el énfasis en el respeto por los derechos humanos de los niños(as) y adolescentes.

\section{La finalidad jurídica de la Patria Potestad}

El sentido y finalidad de la patria potestad como institución jurídica familiar, ha sido influenciada en las últimas décadas, por los cambios en la concepción jurídica del niño(a) y adolescente en las legislaciones de la especialidad. En este trabajo distinguimos tres etapas que muestran una secuencia y un avance progresivo, hacia una construcción jurídica de los niños(as) y adolescentes, como categorías titulares de derechos y deberes.

En las primeras décadas del siglo XX, el rol de contención social de los padres fue enfatizado en las legislaciones de menores latinoamericanas y en los Congresos Panamericanos de la Infancia. Susana Igle- 
sias, recoge las conclusiones de los Congresos, y específicamente, hace referencia a la función de la familia. En el Congreso de Caracas de 1948, señala que correspondía "[...] al Estado la vigilancia y protección del menor desde su concepción hasta cumplir los dieciocho años cuando no fuera ejercida por los padres u otras personas en calidad de guardadores». ${ }^{1}$

Las legislaciones de menores recogieron estas percepciones, contemplándose que la agresión, la desidia o el abandono de los padres, ocasionaba que el menor fuese considerado en "situación irregular», estableciéndose su internamiento para brindarle el control y la "protección" que eran requeridos.

Es así, como esta orientación del rol familiar como espacio de protección y control social, influyó en la razón jurídica de la patria potestad, dándose la necesidad de brindar atribuciones a los padres, que favorecieran al cumplimiento de sus deberes. Recogiendo estos postulados, Manuel Albaladejo sostiene:

"Mientras los hijos son menores de edad los padres tienen muchos deberes hacia ellos, para su protección y formación. Y para cumplirlos y decidir según la conveniencia de cada momento, necesitan amplias facultades sobre la persona y bienes de sus hijos. Llamándose patria potestad al conjunto de éstas, o poder global que la ley otorga a los padres sobre los hijos.»²

Asimismo, autores como Colín y Capitant ${ }^{3}$, y los hermanos Mazeaud ${ }^{4}$, destacan la autoridad de los padres sobre los hijos, como la esencia o finalidad primordial de la institución; sobre el particular, los hermanos Mazeaud muestran la sinonimia entre las expresiones de autoridad y potestad, concepción romana que extiende sus tentáculos

1 Susana Iglesias, Helena Villagra y Luis Barrios, «Un viaje a través de los espejos de los Congresos Panamericanos del Niño». En: Derecho a tener Derecho. Ed. La Primera Prueba. C. A. Venezuela p.149.

2 Manuel Albaladejo, Manual de Derecho de Familia y Sucesiones. Ed. Librería Bosch, Barcelona, 1974, p.148.

3 A. Colin y H. Capitant, citado por Jorge Alcides Uriarte, Patria Potestad. Ediciones Ghersi, Buenos Aires, 1981, p.9

4 Henri, León y Jean Mazeud, citado por Jorge Alcides Uriarte, Patria Potestad. Ediciones Ghersi, Buenos Aires, 1981.p.9 
hasta nuestros días, y que tuvo su origen en el derecho romano al otorgar al padre de familia, poder absoluto sobre los hijos.

En el Código Civil de 1936, al regularse la patria potestad, se contempla entre los derechos-deberes ${ }^{5}$ otorgados a los padres, recurrir a las autoridades policiales y al poder judicial cuando no bastare su autoridad para corregir a sus hijos(as) ${ }^{6}$. Correspondía entonces, a los jueces de menores intervenir, cuando la autoridad en el hogar no era suficiente para el efectivo control hacia los hijos(as).

En una segunda etapa, en la década de los ochenta, la concepción del niño(a) como sujeto de derechos cobró auge, siendo incorporada en las discusiones del mundo académico y en instrumentos internacionales, como la Convención sobre los Derechos del Niño de las Naciones Unidas. En relación a estas nuevas orientaciones doctrinales, Guillermo Borda indica que:

"Hoy está definitivamente triunfante la idea de que la patria potestad implica no sólo derechos sino también deberes; y más aún, que lo que importa primordialmente es la protección de los menores. La legislación moderna, a la inversa de la antigua, ha puesto el acento sobre los deberes y no sobre los derechos de los padres». ${ }^{7}$

Además, el citado autor, agrega que la patria potestad contiene derechos en los padres, pero con ciertos límites, otorgándosele un carácter no absoluto a su ejercicio, a fin de evitar la arbitrariedad y el exceso.

Asimismo, en relación a la patria potestad, Francisco Lledó Yague señala que debe ser entendida como «[...] los deberes de asistencia y protección que corresponden a los padres en relación con los hijos, al tiempo que se fundamenta en un principio de autoridad de los padres» ${ }^{8}$

Al encontrarse aún en sus inicios, la concepción jurídica del niño(a) y adolescente como sujeto de derechos, el Código Civil Peruano de

5 Artículo $398^{\circ}$ del Código Civil de 1936

6 Facultad nuevamente incorporada en nuestra legislación, desde la última modificación del Código de niños y adolescentes (el 7 agosto del 2000).

7 Guillermo Borda, Manual de Derecho de Familia. Editorial Perrot. Buenos Aires, 1988, p.342.

8 Ana Hernán Ortiz, «De las Relaciones Paterno-Filiales». Compendio de Derecho de Familia Civil. Francisco LLedó Yague (ed.) Editorial Dykinson. Madrid, 2000. p. 311. 
1984, mantuvo la misma formula de derechos-deberes de los padres contenida en el código derogado y continuó considerando a los progenitores como los sujetos destinatarios de la patria potestad.

A inicios de la década de los noventa, con la entrada en vigencia del Código de los niños y adolescentes, se atribuye a la patria potestad una connotación distinta, la cual es claramente expresada por Gustavo Bosser, cuando sostiene que:

"No estamos en el campo de los meros derechos subjetivos, organizados sobre la base del interés individual del titular del derecho, sino ante derechos-deberes, que se confieren [...] no sólo atendiendo a sus intereses, sino, principalmente, considerando el interés del otro sujeto (en el caso, el menor bajo la patria potestad), por lo cual, los derechos que se confieren implican correlativos deberes.»'

El Código de Niños y Adolescentes, derogó el Código de Menores entonces vigente, y unificó el tratamiento legislativo de la infancia en un sólo instrumento legal. Este Código, recoge los principios de la Doctrina de la Protección Integral de la Infancia ${ }^{10}$, e introduce modificaciones que buscan erradicar el control social, como la finalidad de la familia. Es así, como suprime, la última parte del inciso que aludía al derecho-deber de corrección de los padres que indicaba: "corregir moderadamente a los hijos y, cuando esto no bastare, recurrir a la autoridad judicial solicitando su internamiento en un establecimiento dedicado a la reeducación de menores».(el subrayado es nuestro).

Además bajo la concepción del niño(a) como sujeto de derechos y en búsqueda del interés superior del niño, la normativa del Código de Niños y Adolescentes está orientada a brindar un papel más activo y protagónico al niño(a) o adolescente, en todo proceso administrativo o judicial, en que sus intereses estén siendo involucrados.

La orientación doctrinal actual, marca una tercera etapa, que busca dar un paso adelante en la vigencia de la condición del niño(a) como

9 Gustavo Bossert y Eduardo Zannoni, Manual de Derecho de Familia. Ed. Astrea. Buenos Aires, 2000.

10 Principios contenidos en la Convención sobre los Derechos del Niño, que orientan la interpretación de los derechos humanos de los niños y que generan un efecto vinculante para el Estado peruano desde su ratificación 
sujeto de derechos y deberes genéricos y específicos, en todos los espacios en que se desenvuelva. Se promueve la identificación de los intereses y necesidades de los niños(as) y adolescentes, los cuales son únicos y en muchos niveles diferenciados de los que corresponden a la madre o al padre.

Con la finalidad de ser coherentes con la nueva orientación doctrinal, se requiere en primer lugar, que la patria potestad varíe su denominación, en razón al significado patriarcal excesivo y abusivo, que se le atribuyó en sus orígenes, y por no permitir una regulación sistemática adecuada.

Adicionalmente, la patria potestad, deberá ser entendida no en función de los padres sino de los hijos. Los derechos y deberes de los hijos en el ámbito familiar, deberá ser su contenido, buscando que el cumplimiento y exigencia de los primeros, sea parte del proceso de formación del nińo(a) y adolescente como persona con dignidad y autonomía.

Un argumento interesante para entender la patria potestad en función de los hijos(as), se centra en su naturaleza de derecho relativo, es decir, esta institución jurídica se extingue cuando los hijos han cumplido su mayoría de edad o cuando han contraído matrimonio a los dieciséis años. Concluyéndose que son los requerimientos o necesidades de los hijos, los que dan origen y sentido a la patria potestad.

Recogemos el sustento filosófico de la patria potestad, el cual ha sido señalado con acierto por Hernán Gómez Piedrahita, cuando alega que «las bases filosóficas sobre las cuales se edifica la institución de la patria potestad son el beneficio y la protección del menor y no el provecho personal de los padres.." ${ }^{11}$

Coincidiendo con esta postura, el Código de Familia de El Salvador, establece que la autoridad parental, (en vez de patria potestad) es "[...] el conjunto de facultades y deberes, que la ley otorga e impone al padre y a la madre sobre los hijos menores de edad o declarados incapaces, para que los protejan, eduquen, asistan y preparen para la vida, y además, para que los representen y administren sus bienes») ${ }^{12}$ (el énfasis es nuestro).

11 Hernán Gomez Piedrahita, Derecho de Familia. Ed. Temis S.A, Santa Fé de Bogota, 1992. p.301.

12 Artículo $206^{\circ}$ del Código de Familia de El Salvador. 
Se evita aludir a los derechos de los padres, indicando que son facultades, las cuales conjuntamente con sus deberes para con los hijos(as), son parte de la patria potestad. Con ello se busca incidir en la condición de sujeto de derechos de los hijos(as) en el ámbito familiar.

Además de estos cambios terminológicos, la visión del hijo como sujeto de derechos, repercute en el rol sociojurídico atribuido a la familia y en las relaciones interpersonales de sus miembros. Sobre estos dos aspectos, Miguel Cillero indica que la «...primacía del interés superior del niño y el reconocimiento del rol preponderante de la familia en la protección integral de sus derechos, [...] deben pasar a constituirse en los fundamentos de la regulación de las relaciones de familia en el ámbito de los niños.» ${ }^{13}$

1. El rol de la familia, específicamente de los padres, es brindar protección, educación y orientación al hijo, a fin que ejerza de manera cierta y efectiva la plenitud de sus derechos, coadyuvando a su desarrollo pleno como sujeto en formación ${ }^{14} \mathrm{y}$ al respeto a su dignidad como ser humano.

Es de interés social, que los padres den cumplimiento a estos deberes, sobre el particular, Javier Peralta Andía ${ }^{15}$, sostiene que la Patria Potestad debe ser entendida como:

"[...] el conjunto de poderes en los cuales se actúa orgánicamente la función social confiada a los progenitores de proteger, educar e instruir a los hijos menores de edad, en consideración a su falta de madurez psíquica y de su consiguiente falta de incapacidad para obrar.» ${ }^{16}$

13 Miguel Cillero, "Evolución histórica de la consideración jurídica de la infancia y adolescencia en Chile». En: Infancia en riesgo social y políticas sociales en Chile. Instituto Interamericano del Niño, Montevideo, 1994. p.83.

14 Sobre el particular, al final del artículo $8^{\circ}$ del Código de Niños y Adolescentes, al enunciarse el derecho a vivir en una familia, se señala que "Los padres deben velar porque sus hijos reciban los cuidados para su desarrollo integral».

15 Javier Peralta Andía, Derecho de Familia en el Código Civil. Editorial Moreno. Lima,

16 En cuanto al origen de las funciones naturales de los padres, Peralta Andía enfatiza en las características de la inmadurez e incapacidad de los hijos, sobre el particular, consideramos que existen mejores argumentos para justificar y señalar su requerimiento, como el deber de resguardo de los derechos de los hijos por los padres, en aras del respeto a su condición de persona como sujeto de derechos. 
Sin embargo, al recogerse el ejercicio de los derechos de los niños(as) como parte de los intereses sociales, se hacen más difusos los límites que marcan la diferencia entre el derecho privado y el derecho público. Miguel Cillero sostiene que:

«El Derecho de Familia es considerado [...] un Derecho intermedio entre el Derecho Privado y el Derecho Público, existiendo legislaciones que lo consideran como un Derecho independiente. Esto se debe a que la familia, dada su especial naturaleza, no constituye un interés meramente individual o privado, sino que representa un valor social y público.»17

En consecuencia, la atribución de una función social a la patria potestad, genera una mayor intervención estatal, puesto que el estado deberá cumplir su rol de garante del cumplimiento de las obligaciones de los padres, valiéndose de instituciones jurídicas, como la suspensión de la Patria Potestad, para sancionar a los padres por la vulneración de algún derecho fundamental del hijo(a).

Esta intromisión del Estado en el ámbito privado no puede ser ilimitada, sólo es social y jurídicamente aceptada, en la medida que busque resguardar los intereses del niño(a) y adolescente, y la intervención garantice evitar un perjuicio mayor.

En relación al tema, Guillermo Borda muestra su desacuerdo con la intervención excesiva del Estado en la vida íntima de la familia, señalando que la patria potestad no se agota en la función social que le es atribuida, ni en los deberes que les corresponde a los padres para el cuidado de los hijos, sino también, en derechos naturales como «[...] el educar a los hijos, plasmar su espíritu, de formarlos de acuerdo con sus ideales morales, religiosos o políticos[...] considerarse y respetarse los derechos que los padres indiscutiblemente poseen. ${ }^{18}$

La intromisión del Estado en el ámbito familiar, ha ocasionado distintas reacciones en la posturas doctrinales, abogándose mayormente, por que se de con la justificación debida y bajo el requerimiento de ciertas limitaciones. 
2. La visión diferenciada de cada uno de los miembros de la familia, favorece una redefinición de las relaciones de los padres para con los hijos(as). La Patria Potestad deberá ser entendida primordialmente, como el conjunto de derechos y deberes que otorgados a los hijos(as) generan deberes y facultades en los padres, es decir, la relevancia estará dada en el cumplimiento del rol que tiene todo progenitor, de brindar los cuidados y las atenciones necesarias para favorecer el desarrollo integral de sus hijos(as), que garantice sus potencialidades como persona.

En relación a los límites de su ejercicio, Francisco Lledó indica que el ejercicio de la patria potestad se deberá realizar «en beneficio de los hijos y de acuerdo con su personalidad». ${ }^{19}$

La referencia a la doctrina, cobra especial relevancia, cuando comprobamos que las relaciones familiares en su interactuar cotidiano, se muestran severamente afectadas por los conflictos de sus miembros.

\section{La suspensión de la Patria Potestad}

La patria potestad es ejercida de manera conjunta por ambos progenitores, su sustento legal se encuentra en el principio de igualdad, contenido en la Constitución Política del Estado. Sólo ante circunstancias que ameritan la protección del hijo, corresponde la suspensión de esta institución con relación al progenitor culpable.

La finalidad jurídica de la suspensión de la Patria Potestad reside en producir una ruptura temporal del vinculo paterno filial, por haberse probado mediante un proceso judicial, que los padres no cumplen con su deber de velar por el desarrollo sano y normal de su hijo.

Una clasificación genérica de las causales de suspensión de la Patria Potestad, resultará esclarecedor. De manera esquemática podemos hacer una división entre aquellas, cuya justificación esta sustentada en situaciones no atribuibles a los padres, o ajenas a su voluntad, que dificultan los cuidados que deben a sus hijos(as); y las referidas, a una vulneración de los derechos de los hijos(as) por sus propios padres.

El supuesto jurídico, es que ya sea de manera voluntaria o involuntaria, los padres no garanticen el resguardo efectivo del ejercicio de 
derechos a sus hijos. Por causas ajenas a su voluntad, podemos nombrar, la declaración de interdicción del padre o la madre y la ausencia judicialmente declarada de los mismos ${ }^{20}$. Mientras que las causales que tienen su origen en la vulneración de los derechos de los hijos(as) por sus padres, están referidas a situaciones como: atentar contra un bien jurídico del hijo (que da lugar a una condena penal al padre) ${ }^{21}$; atentar contra su formación integral (al darle ordenes, consejos o ejemplos que los corrompan); permitir su vagancia o dedicarlos a la mendicidad; el maltrato físico o mental (transgrediendo el padre/madre su deber a la corrección moderada); y finalmente, la causal de negarse a prestar alimentos, (incumpliendo con su obligación de velar por el sostenimiento de su hijo) ${ }^{22}$. Todas estas causales, violentan de manera explícita un derecho otorgado a los hijos, a partir de la institución jurídica de la Patria Potestad.

Un caso especial contemplado en la ley como causa de suspensión de patria potestad, es la separación judicial o divorcio por causal. Este supuesto dificulta ser considerado en esta clasificación, debido a que la probanza de haber incurrido en una causal que generó la separación o el divorcio, no pone en peligro necesariamente algún derecho de los hijos(as). En consecuencia, se requerirá probar en qué medida la causal de separación judicial o divorcio por causal, responde a la racionalidad jurídica de las demás causales señaladas.

Es propio de la suspensión de la patria potestad, su naturaleza temporal, al haberse incorporado en nuestra legislación la factibilidad de su restitución; es la oportunidad que se da a los progenitores de rectificar su conducta y de reestablecer la relación jurídica con sus hijos. Para dicho efecto, será necesario que hayan cesado las circunstancias y/o mutado las conductas, en base a las cuales se declararon probadas las causales, añadiendo la ley, que el juez de familia deberá considerar en su decisión los intereses del hijo.

Resulta difícil reconocer que se requiere probanza para la restitución de la Patria Potestad, cuando la causal de la suspensión ha sido la disolución del vínculo conyugal, por no existir la posibilidad de revertir la situación que acarreó la vulneración de su deber marital y el consecuente divorcio. Situación diferente es la separación judicial, en la

20 Literales a) y b) del artículo $75^{\circ}$ del Código de los Niños y Adolescentes.

21 Podría ser la sentencia judicial de un proceso por omisión a la asistencia familiar, lesiones o violencia familiar donde el directamente agraviado sea el hijo.

22 Literales c), d), e) y f) del artículo $75^{\circ}$ del Código de los Niños y Adolescentes. 
medida que la reconciliación entre los cónyuges todavía es viable, pudiendo variar su condición jurídica de separados. Asimismo, la conducta que acarreó la sentencia de divorcio, puede continuar o puede haber variado; en todo caso, los deberes maritales no subsisten y por lo tanto ya no podrán ser incumplidos, debiendo el juez en consecuencia, pronunciarse sobre la situación del padre/madre actual y la conveniencia de su ejercicio de la patria potestad.

Es así como la temporalidad de la suspensión de la patria potestad, en este caso específico, es cuestionable, en la medida que el Código Civil, es explícito al señalar en el artículo $340^{\circ}$ que «El padre o la madre a quien se haya confiado los hijos ejerce la Patria Potestad con respecto de ellos. El otro queda suspendido en el ejercicio, pero lo reasume de pleno derecho si el primero muere o resulta legalmente impedido». Es decir, el cónyuge culpable del divorcio deberá esperar que su excónyuge fallezca o este legalmente impedido para solicitar la restitución de la Patria Potestad.

\section{Consecuencias de la suspensión de la Patria Potestad}

Los efectos de la suspensión de la patria potestad, están establecidos en el Código de niños y adolescentes y en el Código Civil. La segunda es una norma supletoria de la primera, en la temática de los derechos de la infancia y adolescencia.

En relación a las consecuencias de la suspensión de la patria potestad, el Código Civil de 1984 en su derogado artículo $470^{\circ}$ indicaba que "[...] la pérdida, privación, limitación o suspensión de la Patria Potestad no alteran los deberes de los padres con los hijos», y el artículo $422^{\circ}$ del Código Civil agregaba «[...] los padres tienen derecho a conservar con los hijos que no están bajo su patria potestad las relaciones personales indicadas por las circunstancias."

En la actualidad, con el Código de niños y adolescentes, se mantiene el deber de proveer alimentos para el padre suspendido en la patria potestad, ${ }^{23}$ y está vigente, el artículo referido al resguardo de las relaciones personales de los padres con sus hijos, de acuerdo a las circunstancias; esta precisión final, genera la necesidad de una valoración de cada caso en específico a fin de poder determinar las características de la nueva relación padre-hijo, ha establecerse en la sentencia judicial. 
Cuando se alude a las relaciones personales, se deberá incluir todas aquellas vivencias que son producto de la dinámica familiar y que permiten el desarrollo psicoafectivo del niño(a) o adolescente. No deberá, en consecuencia, obstaculizarse la comunicación y la orientación educativa de los padres.

Será necesario evaluar cada caso, a fin de adoptar las medidas requeridas, cuando existan circunstancias que justifiquen de manera cierta y comprobada, que se pone en peligro el desarrollo integral del hijo(a), al mantener las relaciones personales con su padre. Por ejemplo, cuando el progenitor consume sustancias psicoactivas, o cuando está probado mediante un proceso judicial su actuar delincuencial reiterado, sirviendo lo probado en el proceso de divorcio, para evaluar el probable riesgo del niño o adolescente.

Sobre el particular, la Convención sobre los Derechos del Niño, establece que: «los Estados Partes respetarán el derecho del niño que esté separado de uno o de ambos padres a mantener relaciones personales y contacto directo con ambos de modo regular, salvo si ello es contrario al interés superior del niño. $\aleph^{24}$

La atribución del derecho a mantener relaciones personales con su progenitor/hijo, es fundamental para el análisis de los efectos jurídicos de la suspensión de la patria potestad, ¿de quién es el derecho a mantener las relaciones personales, del padre o del hijo?

Si definimos la Patria Potestad como los derechos y deberes de los padres frente a los hijos(as), abogaremos porque este derecho está referido al padre, (no sólo por una interpretación literal de la norma sino por una lectura sistemática de la institución de la patria potestad), y teniendo como sustento el divorcio sanción, no tendremos dificultad, en limitar el derecho del padre/madre culpable a mantener de una relación personal con sus hijos(as).

Distinta será la conclusión, si recogemos lo indicado por la Convención sobre los derechos del niño; es decir, el titular del derecho a mantener una relación personal es el hijo(a), quedando a criterio del juez, según las circunstancias, plantear en que condiciones se dará.

Discernir quién es el titular de este derecho, es fundamental, al comprobar que los padres suspendidos en la patria potestad no podrán 
tomar decisiones tan decisivas en la vida del niño(a) o adolescente, cuando se trata de una autorización para viaje o contraer matrimonio. En relación a la primera situación, el progenitor(a) titular de la patria potestad podrá llevarse consigo al niño(a) fuera del país, y el derecho a mantener relaciones personales del padre sancionado, se verá en la práctica vulnerado. Con relación al matrimonio del adolescente, este mismo pondrá termino a la patria potestad, sin que pueda el padre/madre sancionado actuar para oponérsele.

Resulta sumamente complejo determinar como se pueden otorgar ciertas atribuciones a los padres que no gozan de la titularidad y ejercicio de la patria potestad, todo en aras de velar por la vigencia de la condición de sujeto de derechos de los hijos(as), evitando que se tomen decisiones con el carácter de represalias, dentro de un conflicto que le corresponde a sus padres.

\section{El sistema del divorcio sanción y su repercusión en la Patria Potestad}

Son variados los argumentos que han sido esgrimidos para justificar los efectos del sistema divorcio sanción en la patria potestad. En relación al tema, Patricia Grosman y Irene Martínez ${ }^{25}$, hacen un recuento de como inicialmente, en la jurisprudencia argentina, se limitaba el derecho a guarda y visita de los hijos(as), a aquellos padres que establecían uniones no formalizadas (nacidos de padres/madres no divorciados al formar una nueva relación pareja) ${ }^{26}$.

Citando fallos judiciales, las autoras en mención, recogen resoluciones referidas, al peligro de afectar la personalidad y desenvolvimiento normal de los hijos(as), al entrar en contacto con la pareja de su padre/madre, dándose la posibilidad de provocar una distorsión de la imagen de familia que guarda el niño(a). Paralelamente, argumentos contrarios, sostuvieron algunos jueces, al indicar que ocultando la nueva familia del progenitor(a), se generaría una percepción negativa hacia el padre/madre, desfavoreciendo su imagen ante el niño.

25 Cecilia Grosman e Irene Martínez, Familias Ensambladas. Editorial Universal, Buenos Aires, 2,000.

26 Cuando el Código Civil argentino no contemplaba el divorcio. 
A partir de la doctrina de la protección integral, el Estado plantea como su principal preocupación velar por lo que más convenga al niño(a), debiendo en consecuencia, contemplarse en la resolución judicial, que la separación judicial y el divorcio por causal, genera una crisis no sólo en los sujetos directamente relacionados al conflicto, sino que de manera inmediata y natural se produce una repercusión negativa en los demás miembros que integran el sistema familiar.

Cuando esta problemática familiar es conocida por el sistema judicial, se produce una dinámica de entradas y salidas que afecta directamente a la familia y a la sociedad en su conjunto; en términos de la sociología jurídica, se aplica el enfoque sistémico, consistente en que se presenta un problema familiar (imput) que ingresa al sistema judicial para ser solucionado y devuelto nuevamente a la sociedad de donde tuvo su origen, generando un nuevo impacto (output) en la dinámica familiar. ${ }^{27}$

En consecuencia, el juez deberá actuar «[...] como una fuerza estructurante en una familia desestructurada $[\ldots]{ }^{28}$. Será necesario que el juez de familia, evalúe las circunstancias de cada caso específico, para pronunciarse sobre la suspensión de la patria potestad. El objeto será evitar que la suspensión de la patria potestad, sea una consecuencia inmediata, una vez que sea probada la causal de divorcio.

En relación al tema, el Código de Familia de El Salvador ${ }^{29}$ brinda nuevos aportes interesantes; en primer lugar no establece la suspensión de la Patria Potestad, frente a la separación judicial o divorcio por causal de los padres. Pero va más allá, de manera expresa señala algunas causales de suspensión de la patria potestad no contempladas en la legislación peruana. Así, su artículo $241^{\circ}$ numeral 2) indica que «El ejercicio de la autoridad parental se suspenderá al padre, o la madre o a ambos, por alcoholismo, drogadicción o inmoralidad notoria que ponga en peligro la salud, la seguridad o la moralidad del hijo" (el subrayado es nuestro).

Si leemos con cuidado las causales establecidas en el Código salvadoreño, descubriremos que algunas coinciden con las consideradas para

27 Giovanni Tarello, Cultura Jurídica y Política del Derecho. Fondo de Cultura Económica. México, 1988. p.410.

28 Eduardo José Cárdenas, La Familia y el Sistema Judicial. Emecé Editores. Argentina, 1988. p.59.

29 Publicado en el Diario Oficial «El Peruano» el 13 de diciembre de 1993. 
un proceso de divorcio en la legislación peruana; entre ellas, el uso habitual e injustificado de drogas alucinógenas o de sustancias que puedan originar toxicomanía, así como la conducta deshonrosa. La diferencia sustancial está dada en que estas situaciones en el Código salvadoreño afecten los derechos a la salud, seguridad y a la integridad moral del niño(a), cifrando en esto su atención; mientras que la ley peruana no las contempla para suspender la patria potestad de manera directa, sino tan sólo, pueden considerarse contempladas en la causal "por darles órdenes, consejos o ejemplos que los corrompan. ${ }^{30}$

Si orientamos nuestro análisis, hacia una interpretación jurisprudencial en la materia, se podrá brindar algunos alcances, que si bien no nos permiten formular conclusiones, sí nos permiten aproximarnos a la manera como la Corte Suprema ha venido resolviendo sobre la temática.

Al referirse a la norma que establece la suspensión de la patria potestad en el divorcio por causal, la Corte Suprema indicó:

"Considerando:

[...]

Cuarto.- Que, la norma acotada responde al criterio establecido por el legislador de considerar las causales de separación de cuerpos así como el divorcio, como una sanción, (llamado también sistema sanción) en la que se imputa al cónyuge culpable la causa de la separación, por ende, merecedor de ciertas restricciones punitivas, como el suspenderle el ejercicio de la patria potestad de los hijos. ${ }^{31}$

En el caso materia de resolución, los padres habían acordado el ejercicio de la patria potestad, mediante un acuerdo conciliatorio y solicitaron a la Corte Suprema, que tenga primacía lo acordado sobre lo indicado por la norma con respecto a los efectos del sistema divorcio sanción.

La Casación denegó tal pretensión, e hizo primar la ley como mandato imperativo (por ser una norma de orden público), considerando que a diferencia de la separación convencional, en el caso específico analizado, existía un cónyuge culpable, no correspondiendo en conse- 
cuencia que los padres se irroguen la facultad de determinar a quién se otorga la patria potestad.

Orientación diferente es la realizada por la Corte Suprema, cuando el demandante alega la aplicación indebida del artículo $81^{\circ}$ del Código de Niños y Adolescentes, referido a la tenencia, al pronunciarse el juez de familia, sobre la suspensión de la Patria Potestad por haberse probado el adulterio de la demandada.

«Considerando:

[...]

Tercero.- Que, [...], en toda medida concerniente al menor debe tenerse en consideración el interés superior del niño, que siendo así y apreciando además lo manifestado voluntariamente por la menor [...], deviene en aplicable las facultades discrecionales del Juez basada en los hechos. Cuarto.- Que, por otro lado la tenencia de la menor a cargo de su progenitor es por naturaleza de carácter provisoria, supeditada a la buena formación, enseñanza, educación y modales que se le implanta y como tal no causa cosa juzgada.. ${ }^{32}$

En este caso, a diferencia del anterior, el argumento esgrimido no tiene su principal fundamento en los efectos del divorcio sanción, sino lo que resulte más favorable para el niño ${ }^{33}$, siendo determinante para proceder conforme al mismo, el escuchar su opinión.

La diferencia sustancial, en ambos casos, estriba en la posibilidad de evaluar de manera autónoma la relación marital, y paralelamente, la repercusión que la conducta del cónyuge culpable, pueda tener en la crianza y educación del hijo. El fortalecimiento de los lazos familiares deberá ser su principal objetivo, ante una situación inevitable de ruptura conyugal.

\section{Lo que deberá considerar el Juez al determinar la Patria Potestad}

1. No dejarse influir por el presupuesto implícito, de que aquel que no ha sabido cumplir con sus deberes maritales, tampoco podrá

33 Refiriéndose al artículo IX del Título Preliminar del Código de Niños y Adolescentes. 
cumplir con los deberes que tienen su origen en la relación paterno filial.

2. Se debe evitar la suspensión automática de la patria potestad, cuando se ha probado una causal de separación judicial o divorcio, evaluando en cada caso en particular, como aminorar los efectos perjudiciales del divorcio en los hijos(as).

3. La elección de la mejor solución, estará condicionada a la solución que resulte más beneficiosa al hijo; sobre el particular O’Donnell sostiene: «[...] en el caso de la disolución de un matrimonio, por ejemplo, los intereses del niño priman sobre las otras personas o instituciones $[\ldots])^{34}$

4. Considerar la opinión del niño y adolescente ${ }^{35}$. Nos resulta todavía algo molesto e incomodo inmiscuir a los hijos en este tipo de procesos, pero dada la naturaleza y complejidad de los intereses en juego, nuestros jueces de familia, deben conocer su opinión para adoptar la mejor solución en relación a la patria potestad. Deberá entenderse que entre los intereses en conflicto se encuentra los del hijo(a), ayudará a este fin, que el juez trabaje con su equipo multidisciplinario (integrado por psicólogos y trabajadores sociales), lo cual le permitirá adquirir la

34 Daniel O’Donnell, «La Convención sobre los Derechos del Niño: Estructura y Contenido". En: Derecho a Tener Derecho. Editorial La Primera Prueba, C.A. Venezuela.

35 La Convención sobre los Derechos del Niño dio las pautas para considerar la opinión del niño en todo proceso donde sus intereses se encuentren involucrados, sobre el particulaí, el artículo $12^{\circ}$ :

1. "Los Estados Partes garantizarán al niño que esté en condiciones de formarse un juicio propio el derecho a expresar su opinión libremente en todos los asuntos que afectan al niño, teniéndose debidamente en cuenta las opiniones del niño, en función de edad y madurez del niño.

2. Con tal fin, se dará en particular al niño oportunidad de ser escuchado en todo procedimiento judicial o administrativo que afecte al niño, ya sea directamente o por medio de un representante o de un órgano apropiado, en consonancia con las normas de procedimiento de la ley nacional»

Paralelamente como norma específica en la materia, el Código de Niños y Adolescentes, en su artículo $9^{\circ}$ sostiene:

"El niño y adolescente que estuvieren en condiciones de formarse sus propios juicios tendrán derecho a expresar su opinión libremente en todos los asuntos que les afecten y por los medios que elijan, [...] , y a que se tenga en cuenta sus opiniones en función de su edad y madurez" 
convicción que requiere para actuar conforme al Interés Superior del Niño.

Con respecto a este derecho a la opinión del niño(a), Miguel Cillero ${ }^{36}$, sostiene que los niños tienen derecho a que antes de tomar cualquier medida respecto a ellos, se evalúe el criterio de protección del máximo de sus derechos, es decir, buscar siempre que en toda decisión judicial que se adopte, se busque priorizar lo que le sea más favorable, y en estos procesos de divorcio, donde se discute cuestiones tan fundamentales como el decaimiento o ruptura del vínculo conyugal, sus intereses sean también tomados en cuenta.

5. Erradicar de la cultura jurídica de los jueces, el antagonismo tan preponderante en estos casos, donde siempre es necesario encontrar un ganador y un perdedor, un inocente y un culpable. Los jueces deberán considerar que estos procesos deben tener las características de un proceso humano, y que aún cuando sea una familia desintegrada, es la familia del niño, con la cual va a tener que convivir, por ello será necesario orientar su trabajo a buscar que este vinculo conyugal disuelto no influya negativamente en las interacción del padre o la madre con el hijo El equipo multidisciplinario del juez podrá favorecer un desempeño más acorde con estos objetivos.

36 Miguel Cillero, «El Interés Superior del Niño en la Convención sobre los Derechos del Niño". En: Infancia, Ley y Democracia en América Latina. Emilio García Méndez y Mary Beloff (eds). Ed, Temis. Buenos Aires, 1999. 